\title{
Hvordan oppnå fri luftvei?
}

\author{
Sammendrag \\ Bakgrunn. Fri luftvei har førsteprioritet \\ i all behandling av syke og skadede. \\ Formålet med denne artikkelen er å gi \\ en oversikt over basale og nye hjelpe- \\ midler og teknikker for lettere å kunne \\ sikre dette.
}

Materiale og metode. Artikkelen er basert på internasjonale algoritmer for optimal behandling av pasienter med akutte luftveisproblemer og forfatternes erfaring fra klinisk arbeid og arrangering av kurs.

Resultater. Den bevisstløse pasient vil ha ufri luftvei fordi tungen glir tilbake og blokkerer. Dette hindrer man med hakeløft og kjevetak, eventuelt supplert med svelgtube. Uten disse aktive grepene må man plassere pasienten i stabilt sideleie og kontrollere at respirasjonsluften passerer fritt. Den ikkepustende pasient må ventileres med enkle midler: munn-til-munn-metoden, luftlommemaske (pocket mask) eller ansiktsmaske og bag. Endotrakeal intubasjon er vanskelig, supraglottiske hjelpemidler er lettere og tryggere å bruke. Anestesileger kan bruke spesialutstyr når det er spesielt vanskelig å sikre luftveien. Intubasjon med bronkosop hos spontanpustende pasient er rutine i sykehus når det er forventet svært vanskelig tilgjengelig luftvei. Direkte tilgang til trachea kan gjøres enten som kirurgisk nødtrakeotomi eller med ulike punksjonsteknikker.

Fortolkning. Å kunne opprettholde fri luftvei med enkle midler hos en bevisstløs er av vital betydning. Får ikke pasienten luft ned i lungene, vil oksygenmangelen bli livstruende og kunne føre til hjertestans og cerebral iskemi i løpet av 5-6 minutter. Alle leger bør kunne ventilere med ansiktsmaske og bag. Intubasjon og trakeotomi bør bare utføres av øvet personell.
Carl Eivind Bjerkelund

Anestesiavdelingen

Oslo universitetssykehus, Ullevål

Per Christensen

Anestesiavdelingen

Sykehuset Innlandet, Hamar

\section{Stein Dragsund}

Anestesi- og akuttklinikken

St. Olavs hospital

\section{Petter Aadahl}

petter.aadahl@ntnu.no

Institutt for sirkulasjon og bildediagnostikk Norges teknisk-naturvitenskapelige universitet St. Olavs hospital

7006 Trondheim

og

Anestesi- og akuttklinikken

St. Olavs hospital

$\AA$ kunne opprettholde fri luftvei hos en bevisstløs pasient er av vital betydning for sikker anestesi. Denne forståelsen bidro til dramatisk reduksjon av den perioperative mortalitet ved utviklingen av moderne anestesi fra 1940 (1). Nordens første anestesiolog, Torstein Gordh, publiserte i 1941 sin første artikkel nettopp med tittelen Den fria luftvägen (2). Men til tross for at man legger stor vekt på dette, er kritisk lavt oksygeninnhold i blodet som følge av blokkert luftvei fortsatt årsak til anestesirelatert død eller skade. Formålet med denne artikkelen er å gi en oversikt over basale og nye hjelpemidler og teknikker for lettere sikring av fri luftvei.

\section{Materiale og metode}

Denne oversikten bygger på dominerende internasjonale algoritmer (3-5) tilpasset norske forhold og på den erfaring forfatterne har fått gjennom klinisk arbeid og ved gjennomføringen av to norske kurs i avansert luftveishåndtering $\mathrm{i}$ regi $\mathrm{av}$ Scandinavian Society of Anaesthesiology and Intensive Care Medicine.

\section{Primær sikring av pasientens luftvei} Etter retningslinjene for basal hjerte-lungeredning (6) skal man hos bevisstløse først gjøre kjeveløft, slik at luftveien er åpen. Deretter vurderes pustekvaliteten i over ett minutt før man legger en som puster selv i sideleie - dette for å hindre at en pasient med inadekvat agonal respirasjon blir lagt på siden. Er man usikker på om det er adekvat ventilasjon når luftveien er åpen, skal man starte hjerte-lunge-redning.

En pasient som ikke puster, må man ven- tilere med ansiktsmaske og bag, luftlommemaske (pocket mask) eller munn-til-munnmetoden. Maskeventilasjon kan være vanskelig. Det er viktig at man på samme tid bøyer pasientens hode godt tilbake og forsøker å trekke kjeven opp og frem. Å ventilere en person som har tett ansiktsmaske krever øvelse. I akuttsituasjoner er det lettere for uøvde å bruke en luftlommemaske. Den kan man holde med begge hender og så blåse gjennom munnstykket (fig 1).

Luftveien kan også blokkeres av fremmedlegemer, infeksjoner og svulster. Ved akutt oppstått luftveisobstruksjon skal Heimlichs manøver (press i epigastriet) prøves og fremmedlegemet fjernes med fingrene hvis det er lett å nå det. Øvet personell vil kunne se ned i svelget med laryngoskop og fjerne fremmedlegemet med tang eller sug. Blokkering av luftveien kan forekomme ved spesifikke infeksjoner i epiglottis eller larynx, men også som følgetilstand etter annen øvre luftveisinfeksjon (abscesser). Svulster kan også gi rask forverring av et sykdomsbilde, med lufthunger, stridor, sikling, uro og engstelse, eventuelt panikk. Bronkospasme gir ekspiratorisk stridor, mens blokkerte øvre luftveier gir inspiratorisk stridor, der brystkassen suges inn i inspiriet. Luftveisobstruksjon behandles med oksygen og assistert ventilasjon med ansiktsmaske og bag. Man bør unngå bruk av potente sedativer og opioider, som kan true egenrespirasjonen.

\section{Intubasjon}

Anestesipersonell intuberer pasienter i forbindelse med resuscitering, narkose, respiratorbehandling og transport. En ikke-erkjent feilintubasjon fører raskt til døden. Siden

\section{Hovedbudskap}

- Fri luftvei må sikres hos alle bevisstløse

- Det skal gis oksygen når dette er tilgjengelig. Det kan være avgjørende for utfallet av alvorlige luftveisproblemer

- Intubasjon bør bare gjøres av anestesipersonell

- Kontinuerlig trening og opplæring er nødvendig både for anestesipersonell og andre faggrupper med akuttfunksjoner, og ved alle akuttsykehus bør det være beredskap for nødtrakeotomi 


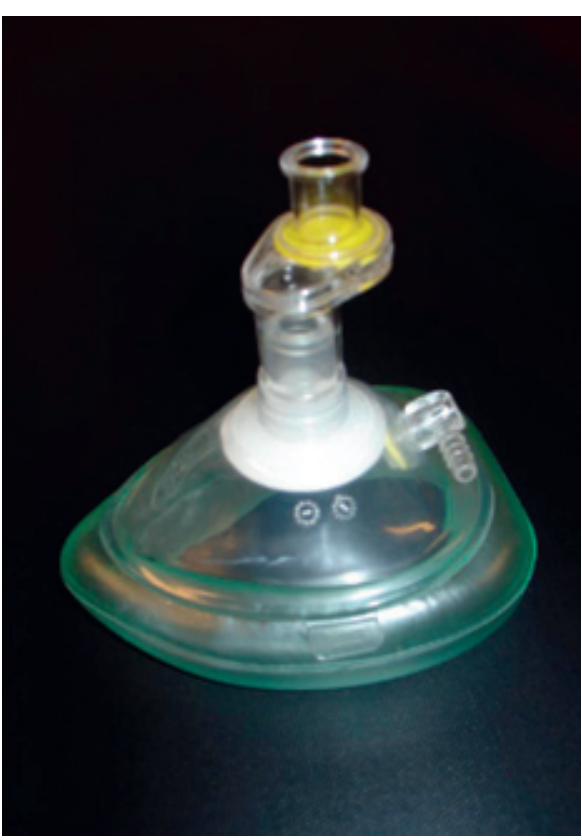

Figur 1 Luftlommemaske (pocket mask)

antallet intubasjoner i sykehus er redusert, bl.a. på grunn av økende bruk av larynxmaske, må intubasjonskompetansen holdes på færre hender enn før - dvs. kun anestesipersonell, som er de eneste som får nok praktisk øvelse (7). Vi beskriver metoden kort.

Ved intubasjon bør pasienten helst ligge $\mathrm{i}$ ryggleie med ekstendert nakke. Adipøse legges til rette med puter slik at øreinngang og sternum er i samme høyde. Laryngoskopet holdes $\mathrm{i}$ venstre hånd og føres inn i munnen slik at det fanger tungen og drar den helt over mot venstre. Ved å trekke i skaftets retning løfter man mandibel og tunge ut av synsfeltet slik at man ser fra munnen ned forbi epiglottis til larynx. Cormack \& Lehane laget en gradering av innsynforholdene ved direkte laryngoskopi som er blitt internasjonal standard (8) (fig 2). Tuben føres ned gjennom stemmespalten til spissen er ca. 20-22 cm forbi tannrekken. Tubens oppblåsbare mansjett (cuff) hindrer at den disloseres og beskytter luftveiene mot aspirasjon av mageinnhold. Tubens leie kontrolleres ved inspeksjon, grundig auskultasjon over begge lunger og med kapnografi der dette er tilgjengelig. Kapnografi er upålitelig ved sirkulasjonsstans.

Tuben kan også legges nasalt. Den er da trædd utenpå et sugekateter som fungerer som ledewire i nese/svelg og motvirker neseblødning. Tuben styres ned gjennom larynx ved direkte laryngoskopi og Magills tang. En «blind» nasal teknikk kan føre til målet $i$ spesielle situasjoner, men vi anbefaler bruk av visuelle teknikker.

Barn har høytliggende larynx og spissere epiglottis, og dimensjonene er mindre enn hos voksne, men teknikkene for intubasjon og luftveissikring er i hovedsak de samme.

Det finnes forskjellig supraglottisk utstyr som er tryggere å bruke for helsepersonell som ikke kan eller skal intubere. Larynxmasken ble introdusert i anestesiologisk praksis så sent som på slutten av 1980-årene, men ble raskt en etablert metode for å sikre fri luftvei under anestesi. Det er de siste årene kommet mange alternativer til larynxmasken, eksempelvis Larynxtube og I-gel. Disse er smalere og lettere å legge ned og er trolig derfor blitt standard luftveissikring ved hjertestans i mange ambulanser (fig 3, fig 4).

\section{Luftveisproblemer og algoritmer}

For å slippe å tenke nytt i krisesituasjoner er det laget algoritmer for optimal behandling av pasienter med akutte luftveisproblemer $(9,10)$. Algoritmen består av generelle råd og et kart der resultatet av ulike tiltak skal utløse nye handlinger. Det er viktig å ha en plan $\mathrm{B}$ og en plan C når plan A svikter! Oksygenmangel er den største trusselen og må prioriteres. Oksygen, hvis det er tilgjengelig, skal tilføres uten opphold. For alle som håndterer luftveisproblemer gjelder:

- Tilkall hjelp tidlig

- Prioriter ventilasjon med metoder som delvis fungerer fremfor stadig nye forsøk på å få luftveisutstyr på plass

Anestesilegene stiller seg følgende spørsmål hver gang de møter pasienter med luftveisproblemer:

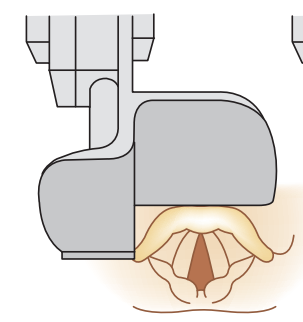

Grad 1

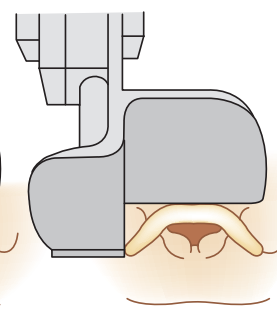

Grad 2

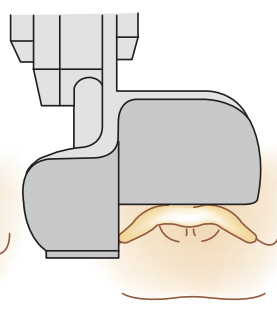

Grad 3

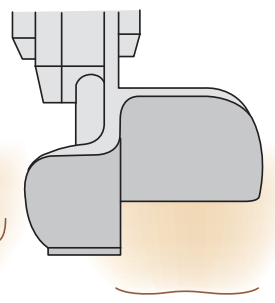

Grad 4

Figur 2 Gradering av innsynsforhold til larynx ved direkte laryngoskopi etter Cormack \& Lehane (8). a) Grad 1 (hele larynx synlig). b) Grad 2 (epiglottis og aryregionen synlig). c) Grad 3 (bare epiglottis synlig). d) Grad 4 (epiglottis ikke synlig)

- Er det tegn som tyder på at pasienten ikke vil kunne overtrykksventileres med maske og bag?

Risikofaktorer for dette er skjegg/bart, overvekt, manglende tenner, høy alder og snorkeproblemer i sykehistorien. Svelgtube og nesesvelgtube kan gjøre maskeventilasjonen lettere. Larynxmaske eller andre supraglottiske hjelpemidler kan prøves hvis ventilasjon med ansiktsmaske eller luftlommemaske (pocket mask) ikke fungerer.

- Er det tegn som tyder på at pasienten vil være vanskelig å intubere?

Det er ingen god test som enkeltvis eller i kombinasjon med andre identifiserer de pasientene som er vanskelige å intubere, men en enkel gjennomgang av risikofaktorer kan øke årvåkenheten. Tidligere intubasjonsproblemer blir journalført, og pasienten får et «risikokort» til å ha i lommeboken. Liten kjeve/hake og fremstående fortenner, nedsatt gapeevne, stiv nakke og trange forhold i svelget pga. stor tunge, tumor, ødem eller skade gir økt risiko for intubasjonsproblemer. Siden man som regel ikke kan forutse problemer, vil alle pasienter puste rent surstoff før narkoseinnledning.

- Er det mulig å legge en kanyle for direkte tilgang på halsen?

Subkutant emfysem, ødem, adipositas eller kyfoskoliose kan gjøre nødtrakeotomi vanskelig eller uaktuelt. Forventes det intubasjonsproblemer, er det viktig å unngå medikamenter som fratar pasienten spontanventilasjonen. Spontanventilasjon sikrer at man kan gi oksygen og vinne tid, men gjør det også lettere å finne frem i luftveien når man bruker avanserte metoder for å intubere.

\section{Bronkoskopi}

Bronkoskopisk intubasjon hos spontanpustende lett sedert pasient er gullstandard ved kjent eller forventet vanskelig luftvei i sykehus. I noen tilfeller kan teknikken også benyttes ved uventet vanskelig intubasjon. Begrepet «våken intubasjon» kan høres fryktinngytende, men faktum er at riktig gjennomført er dette en skånsom metode og ingen traumatisk opplevelse. Erfaring, god informasjon, trygghet, en klar og veloverveid plan, riktig gjennomført lokalbedøvelse og lett sedasjon gjør dette til en trygg prosedyre. Tryggheten ligger $\mathrm{i}$ at pasienten er våken, puster spontant $\mathrm{g}$ har bevarte reflekser. Prosedyren kan lett avbrytes og nødvendige tiltak settes inn i god tid hvis det skulle oppstå problemer. Vi anbefaler liberal bruk av denne teknikken for å gi tilstrekkelig treningsvolum til anestesilegene.

Pasienten sederes med kombinasjoner av analgetika og sedativer. Lokalanestetika sprayes i svelget og injiseres i trachea for start. Oral eller nasal tilgang velges. Slimhinneanestesi via bronkoskopet gis i tillegg ved vanskelige partier (larynxinngang og trachea). Bronkoskopet styres mot larynx, 
finner stemmespalten og går ned i trachea til like ovenfor carina. Synet av carina er tegnet på at man er kommet rett. Når tuben føres ned, har den lett for å bli hengende i larynxinngangen. Dette løses som regel ved å dreie den $90^{\circ}$ mot klokken. Da legger den seg inntil bronkoskopet og føres greit ned $\mathrm{i}$ trachea. Når tubens leie er kontrollert, kan narkosen innledes. Koniske spesialtuber som legger seg tettere inntil bronkoskopet kan gjøre nedføringen lettere. Ved uventet vanskelig intubasjon der narkosen allerede er innledet, må pasienten ventileres og bronkoskopet brukes gjennom ansiktsmaske eller intubasjonslarynxmaske (11).

\section{Spesialutstyr}

Det utvikles stadig nye produkter til bruk ved vanskelig luftvei. Ingen av disse løser problemet $\mathrm{i}$ alle situasjoner, så avdelingene må sikre seg ved å ha noen få av dem som utfyller hverandre. De fleste anestesiavdelinger har laget akuttbokser med utstyr til hjelp ved luftveisproblemer, og personellet øver i bruken av det. En kort oversikt over de viktigste utstyrsgruppene gis her, ellers henvises det til spesiallitteratur $(12,13)$.

\section{Ledesonde}

Hvis man ser epiglottis, men ikke larynxinngangen når man skal intubere - Cormack \& Lehanes grad 3 (fig 2) - kan man gjøre et forsøk med en bougie/ledesonde med vinklet tupp som man forsiktig fører inn bak epiglottis. Hvis sonden entrer oesophagus, vil den gli helt ned i ventrikkelen, men i trachea vil man kjenne at spissen hopper nedover bruskringene og sonden vil stoppe ved carina $(25 \mathrm{~cm})$ eller $5-6 \mathrm{~cm}$ lenger ned i høyre hovedbronkie. Da kan sonden brukes som guide for en vanlig tube som roteres $90^{\circ}$ mot klokken for at spissen ikke skal henge seg opp i larynxinngangen. Det anbefales at man alltid går ned i tubestørrelse ved akutte luftveisproblemer.

\section{Supraglottiske hjelpemidler}

Larynxmasker og andre supraglottiske hjelpemidler (fig 3, fig 4) kan sikre luftveiene delvis i en krisesituasjon. Adekvat ventilasjon oppnås imidlertid bare hvis larynx er åpen, og de gir ingen fullgod sikring mot aspirasjon av mageinnhold til lungene ved høyt trykk i abdomen. Noen av hjelpemidlene har kanal for suging $i$ oesophagus (LMA-supreme/ProSeal, Larynxtube LTSII, I-gel) og kan lede en tube ned i larynx (LMA-Fasttrach, I-gel, Cobra). Det er en viktig fordel at man kan ventilere pasienten med slike hjelpemidler mens man gjennom dem når trachea med en tube, enten blindt eller helst visuelt med fiberoptikk (bronkoskop eller en enkel ikke-styrbar fiberoptisk sonde som ligger inni tuben).

\section{Laryngoskop med spesialblad}

I mange situasjoner med vanskelig intubasjon klarer man ikke å se rundt tungeroten
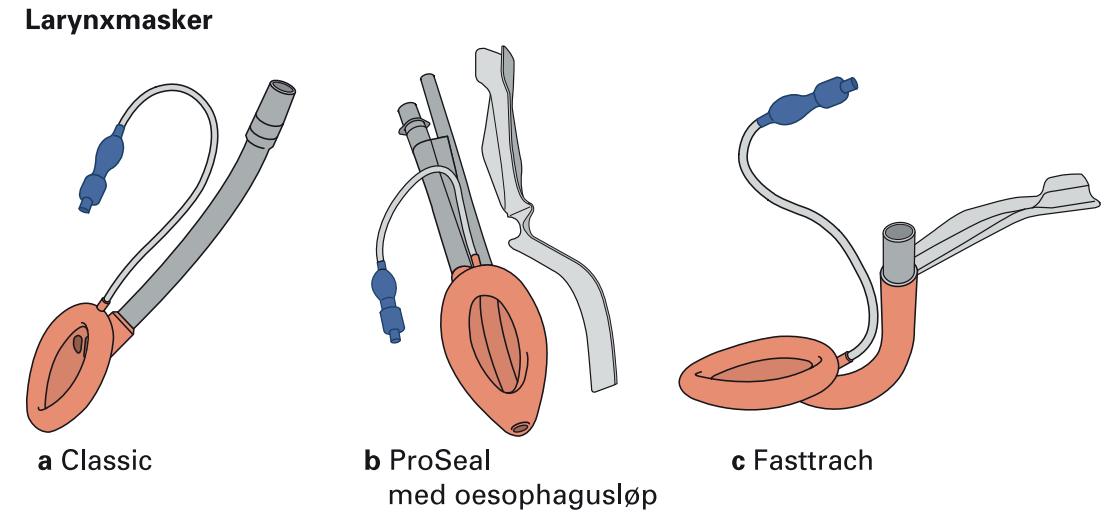

c Fasttrach med oesophagusløp

Alternative supraglottiske

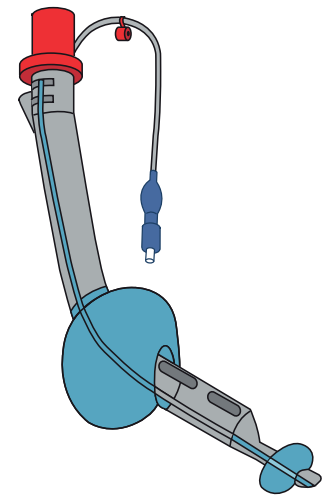

d LTS-II (larynxtube)

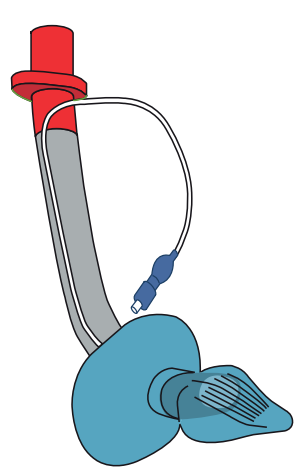

e Cobra

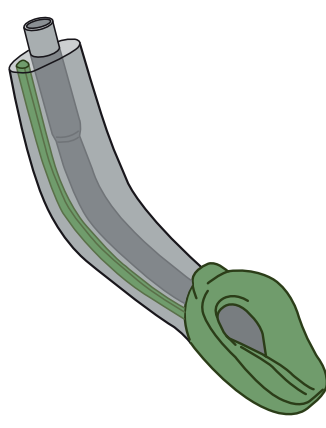

f l-gel
Figur 3 Larynxmasker og alternativt supraglottisk utstyr. al Classic larynxmaske uten oesophagus (øp. b) ProSeal larynxmaske med oesophagus løp. c) Fasttrach intubasjonslarynxmaske uten oesophagusløp. d) Larynxtube LTS-II med oesophagusløp. e) Cobra larynxtube uten oesophagusløp, kan intuberes gjennom. f) I-gel larynxtube med gel i stedet for ballong, har oesophagusløp og kan intuberes gjennom

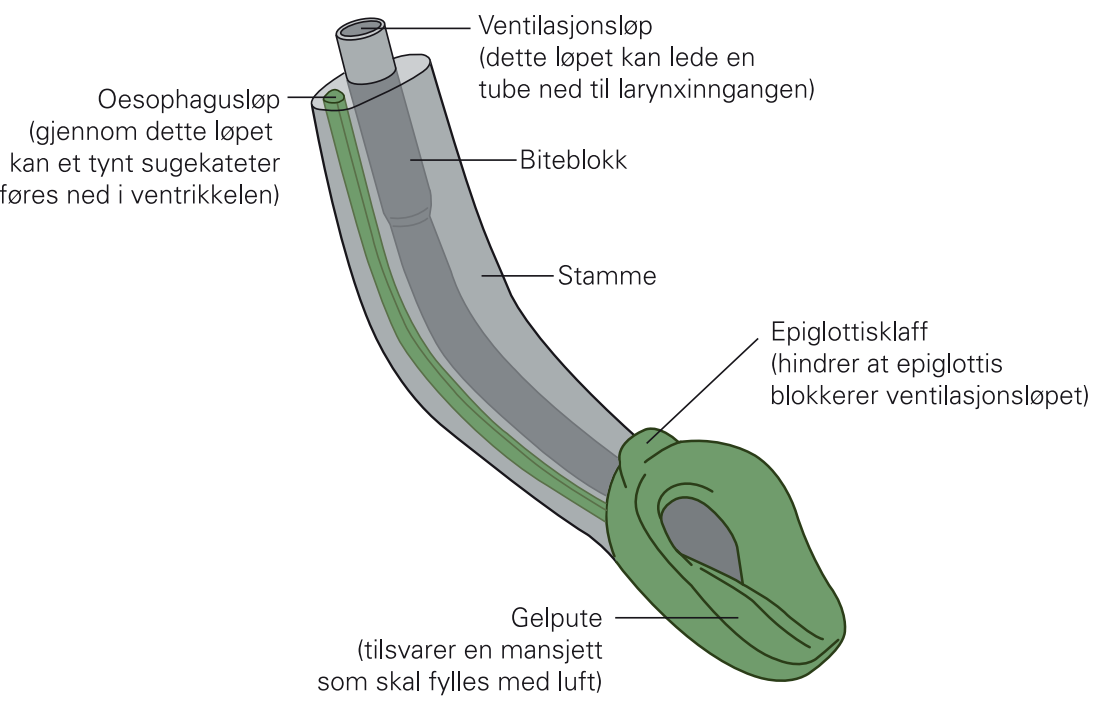

Figur 4 Detalj av l-gel larynxtube. Gjennom ventilasjonsløpet kan man lede en tube ned til larynxinngangen. Epiglottisklaffen hindrer at epiglottis blokkerer ventilasjonsløpet. Gelputen tilsvarer en mansjett som skal fylles med luft. Gjennom oesophagusløpet kan man føre et tynt sugekateter ned i ventrikkelen 
ned til larynx. Dersom pasienten har god nakkebevegelighet, kan et laryngoskop med rett blad rette ut vinkelen og «fange» epiglottis slik at en tube kan ledes ned. Laryngoskop med bevegelig blad er etter vår erfaring til liten hjelp i praksis.

\section{Spesiallaryngoskoper}

Antallet spesialverktøy til «å se rundt hjørner» med er stadig økende. Disse er mer robuste enn fleksible fiberskop, som lett kan få skader ved bruk i akuttsituasjoner. Det kan være prismebaserte, med digitalt vidvinkelkamera eller stive optiske ledesonder. Slike hjelpemidler er nesten like kostbare som fleksible bronkoskoper, men de er mer robuste og vil etter vår erfaring kunne løse uventede luftveisproblemer raskere.

\section{Alternativer til optiske hjelpemidler}

De optiske hjelpemidlene blir vanskelige å bruke når blødning kan dekke linsene. Alternativt kan man i slike situasjoner benytte lysstilett, hvor man følger lyset fra utsiden av halsen, eller retrograd intubasjon, der en ledemandreng træs inn på halsen og fiskes ut av munnen og tuben træs ned over denne. Slik teknikk har vært vellykket ved svære skader på ansikt og hals, men forutsetter at pasienten puster spontant.

\section{Når man verken får oksygenert, ventilert eller intubert}

Når alle vanlige hjelpemidler er prøvd uten at man har lyktes, når pasienten brått blir helt tett eller ved tilstander hvor man vil forvente umulige intubasjonsforhold (svært ødem, tumor, ansiktstraumer), må man en sjelden gang akutt anlegge en nødluftvei.

\section{Punksjon av membrana cricothyreoidea/krikotyrotomi}

Alle anestesileger bør kunne punktere membrana cricothyreoidea med nål og lokalisere trachea ved hjelp av luftaspirasjon i en væskefylt sprøyte og slik vinne tid ved hjelp av høytrykksinnblåsing av oksygen (jetventilasjon). Man kan legge inn en ledewire gjennom nål (Seldingers teknikk) og dilatere opp for en nødkanyle (Melker Emergency Cricothyrotomy Catheter, Cook Medical) eller bruke ulike kanyler av typen «kateter over nål» (14). Dersom spesialutstyr ikke er tilgjengelig, kan man gjøre en krikotyrotomi ved hjelp av en kort incisjon gjennom membrana cricothyreoidea og innleggelse av en vanlig tube eller trakealkanyle.

\section{Nødtrakeotomi}

Åpen kirurgisk trakeotomi kan gjøres som nødprosedyre av kirurger, øre-nese-hals-kirurger eller kjevekirurger som har erfaring med metoden fra elektiv kirurgisk virksomhet. Imidlertid er det ikke krav om åpen trakeotomi i utdanningen i generell kirurgi. Læringsarenaen er også endret, i og med at perkutan dilatasjonstrakeotomi har erstattet den åpne kirurgiske teknikken. Det er enklere, billigere, mindre ressurskrevende og innebærer færre postoperative komplikasjoner $(15,16)$. I Norge blir det trolig gjort minst 500 trakeotomier årlig, og mer enn halvparten av disse blir sannsynligvis utført med perkutan teknikk av anestesileger ved intensivavdelinger. Erfarne operatører kan utføre inngrepet som nødprosedyre på 1-2 minutter. Ved alle sykehus der man behandler øyeblikkelig hjelp-pasienter, må man ha beredskap for akutt trakeotomi. Perkutan punksjonstrakeotomi utført av anestesilege vil være en viktig del av prosedyren for nødtrakeotomi.

\section{Opplæring og trening}

Vi har beskrevet hvor viktig korrekt luftveishåndtering $\mathrm{er}-\mathrm{ikke}$ bare $\mathrm{i}$ hverdagen på operasjonsstuen, men også for dem som behandler pasienter utenfor sykehus. Opplæring og trening i diagnostikk og korrekt håndtering av luftveisproblemer utgjør en viktig del av anestesipersonellets utdanning. I tillegg til generell opplæring i avdelingen arrangeres det mange praktisk rettede kurs for alt helsepersonell med akuttfunksjoner både i og utenfor sykehusene.

\section{Konklusjon}

Å opprettholde fri luftvei med enkle midler hos en bevisstløs person er av vital betydning. Får ikke pasienten luft ned i lungene, vil oksygenmangelen bli livstruende og kunne føre til hjertestans og cerebral iskemi i løpet av 5-6 minutter. Både intubasjon og trakeotomi er avanserte teknikker med bety- delig risiko og bør derfor bare utføres av personell som har tilstrekkelig praktisk trening.

Oppgitte interessekonflikter: Ingen

Litteratur

1. Gordh T. Aktuella narkosproblem. Läkartidningen 1941; 38: 2374-81.

2. Lagerkranser M. Den fria luftvägen. I: Halldin MB Lindahl GE, red. Anestesi. Stockholm: Liber AB, 2000: 215-42.

3. Practice guidelines for management of the difficult airway: an updated report by the American Society of Anesthesiologists Task Force on Management of the Difficult Airway. Anesthesiology 2003; 98: $1269-77$

4. Berlac P, Hyldmo PK, Kongstad P et al. Pre-hospital airway management: guidelines from a task force from the Scandinavian Society for Anaesthesiology and Intensive Care Medicine. Acta Anaesthesiol Scand 2008; 52: 897-907.

5. Lecky F, Bryden D, Little R et al. Emergency intubation for acutely ill and injured patients. Cochrane Database Syst Rev 2008; nr. 2: CD001429. DOI: 10.1002/14651858.CD001429.pub2

6. Norsk Resuscitasjonsråd. Nye norske retningslinjer 2005. BHLR - norske retningslinjer 2005. www.nrr.org/index1.html (18.1.2009).

7. Castren M. Pre-hospital airway management time to provide the same standard of care as in the hospital. Acta Anaesth Scand 2008; 52: 877-8.

8. Cormack RS, Lehane J. Difficult tracheal intubation in obstetrics. Anaesthesia 1984; 39: 1105-11.

9. Henderson JJ, Popat MT, Latto IP et al. Difficult Airway Society guidelines for management of the unanticipated difficult intubation. Anaesthesia 2004: 59: 675-694.

10. Bardenheuer HJ, Forst H, Rossaint R et al. Airway management. Anaesthetist 2007; 56: 837-57.

11. Danha RF, Thompson JL, Popat MT et al. Comparison of fibreoptic-guided orotracheal intubation through classic and single-use laryngeal mask airways. Anaesthesia 2005; 60: 184-8.

12. Lavery GG, McCloskey BV. The difficult airway in adult critical care. Crit Care Med 2008; 36 : $2163-73$.

13. Nolan JP, Soar J. Airway technique and ventilation strategies. Curr Opin Crit Care 2008; 14: 279-86.

14. Fikkers BG, van Vugt S, van der Hoeven JG et al. Emergency cricothyrotomy: a randomised crossover trial comparing the wire-guided and catheterover-needle techniques. Anaesthesia 2004; 59: $1008-11$

15. Ciaglia P, Firsching R, Syniec C. Elective percutaneous dilatation tracheostomy. A new simple bedside procedure; preliminary report. Chest 1985 ; 87: $715-9$.

16. Delaney A, Bagshaw SM, Nalos M. Percutaneous dilatational tracheostomy versus surgical tracheostomy in critically ill patients: a systematic analysis. Crit Care 2006; 10: R55.

Manuskriptet ble mottatt 19.11. 2008 og godkjent 21.1. 2010. Medisinsk redaktør Siri Lunde. 